\title{
Factors Affecting Lower Limb Amputation following Arterial Bypass Surgery
}

Chumpon Wilasrusmee*, Piya Lebkhao, Panuwat Lertsittichai and Napaphat Proprom

Department of Surgery, Faculty of Medicine Ramathibodi Hospital, Mahidol University, Bangkok, Thailand

\begin{abstract}
Study background: To identify important risk factors for subsequent amputation within one year after surgery in patients with acute lower limb ischemia undergoing distal arterial bypass.

Methods: A chart review of patients undergoing distal vascular bypass for lower limb ischemia within the 5-year period between 2006 and 2011 was done. All patients were followed for at least one year. The outcome of interest was the need for amputation of the treated limb within one year after bypass surgery. Potential risk factors associated with the need to perform amputations were abstracted from the medical charts. Logistic regression and chi-square
\end{abstract} tests were used to identify significant associations between risk factors and amputation.

Results: Of 128 patients reviewed, only $18(14 \%)$ had amputations within one year. Although there was a trend for increased risk of amputation for patients with a history of smoking, DM, renal dysfunction, presenting with rest pain, lower $\mathrm{ABI}$, multilevel disease, circumferential thickening of the stenosis, and lower risk for patients taking postoperative antiplatelets (but not anticoagulants), the only significant risk factor at the $5 \%$ level were poorly controlled diabetes mellitus after operation and cerebrovascular disease.

Conclusion: A few well-known risk factors were associated with increased risk of early amputation after arterial bypass surgery.

Keywords: Chronic arterial occlusion; Lower limb ischemia; Cerebrovascular disease; Diabetes mellitus

\section{Introduction}

Limb salvage is the primary goal in management of peripheral arterial occlusive disease (PAOD), especially in patient with critical limb ischemia [1-3]. Tentative conclusions might be drawn by examination of the outcome of surgery for PAOD as measured by the rate of amputation [4]. Evaluation of therapeutic effectiveness of interventional procedures used to treat peripheral arterial occlusive disease (PAOD) requires use of several outcome measures that assess factors that affect patients directly (e.g., survival, amputation-free survival, quality of life, and pain relief), and clinical measures (e.g., laboratory test measurement) [5-7].

To evaluate the long-term outcome of revascularization procedures for PAOD at the population level, survival and major amputation-free survival rates should be used, because they provide more clinically accepted estimates compared with the correlation between utilization rates for revascularization and amputation procedures, which have been used to describe outcome in previously published reports in the literature [8].

Several population-based studies have decreased rate of amputation in association with increased use of revascularization procedures $[1,2,4,5,8]$. On the other hand some studies showed no changes in lower extremities amputation rates [9-11]. The assumption in these studies is that if revascularization procedures avert the need for amputation in some patients, then a negative correlation should exist between rates of amputation and revascularization procedures.

Risk of amputation following revascularization procedures was positively associated with type of procedure, black race, uninsurance/ Medicaid, and diabetes status [12]. Risk of death was also higher following bypass surgery while this might reflect underlying severity of disease. Patient education, screening, and optimal care of lower extremities should be emphasized to peripheral vascular disease (PVD) patients at an early stage of the disease process [12].
For several risk factors, diabetes-related amputation rates exhibit high regional variation, even after age, sex, and race adjustment [13]. Only patients receiving dialysis, and not patients with milder degrees of renal insufficiency, appear to be at higher risk for limb loss after revascularization, compared with patient with normal renal function [14].

\section{Materials and Methods}

\section{Study design}

A retrospective hospital based cohort study utilizing administrative database in Ramathibodi hospital was conducted from 1 January 200631 December 2011.

\section{Data source}

The study was conducted at the Ramathibodi hospital. Case record for bypass surgery from Ramathibodi hospital discharge was analysed. The database record contains information on patient demographics, underlying diseases of patients (diabetes mellitus, hypertension, coronary artery diseases, congestive heart failure, cerebrovascular accident, renal insufficiency), diagnosis and procedures. The diagnosis codes were based on International Classification of Diseases (ICD) 10th division while operations were based on ICD-9 CM.

*Corresponding author: Chumpon Wilasrusmee, MD, MSc, Department of Surgery, Ramathibodi Hospital, 270 Rama VI Road Bangkok 10400 Thailand, Tel: 662-201 1315; Fax: 662-201-1316; E-mail: racwl@mahidol.ac.th

Received June 18, 2012; Accepted August 01, 2012; Published August 06, 2012

Citation: Wilasrusmee C, Lebkhao P, Lertsittichai P, Proprom N (2012) Factors Affecting Lower Limb Amputation following Arterial Bypass Surgery. J Diabetes Metab 3: 208. doi:10.4172/2155-6156.1000208

Copyright: ( $\odot 2012$ Wilasrusmee C, et al. This is an open-access article distributed under the terms of the Creative Commons Attribution License, which permits unrestricted use, distribution, and reproduction in any medium, provided the original author and source are credited. 


\section{Identification of cases}

A procedure code for lower extremities arterial bypass surgery code 39.29 , the code 39.25 were considered for aorto-ilio-femoral bypass.

Characteristics of patients such as presence of diabetes mellitus, hypertension, coronary artery diseases, congestive heart failure, cerebrovascular accident, renal insufficiency were abstracted from medical records. History of smoking was recorded.

Patients were followed from date of surgery until the occurrence of the outcome of interest (major amputation within 1 year) or until last follow up, whichever comes first. Major amputation was defined as through-ankle amputation, below knee amputation, or above knee amputation

\section{Statistical analysis}

Logistic regression and chi-square tests were used to identify significant associations between risk factors and amputation. All $P$ values reported were two-tailed and were considered significant at 0.05 , statistical analysis were perform with SPSS.

\section{Results}

This study was undertaken to determine the outcome of revascularization procedures of $\mathrm{PAOD}$ on a hospital basis by reviewed data in Ramathibodi hospital between 2006 and 2011. The overall amputation rate in one year was 18 patients in 128 patients (14\%) after revasucularization procedure. Mean of ABI in affected limb in amputation group and non-amputation group were 0.46 and 0.53 respectively. Mean of $\mathrm{ABI}$ in contralateral side in amputation group and no- amputation group were 0.82 and 0.86 respectively. Patient baseline characteristics are summarized in table 1.

For many parameters in these 128 patients reviewed in Ramathibodi Hospital in between 1994-2004, there was a trend for increase risk of amputation for patients with history of smoking, diabetes mellitus, renal dysfunction, presenting with rest pain, lower ABI, multilevel disease, circumferential thickening of the stenosis, and lower risk for patients taking postoperative antiplatelets (but not in anticoagulant group), the only significant factors were poorly controlled diabetes mellitus and cerebrovascular diseases. There was no correlation between risk of

\begin{tabular}{|l|l|l|l|}
\hline & No Amputation & Amputation & P value \\
\hline Number of patients & 110 & 18 & \\
\hline Mean age (y) (+) SD & $61.1(14.7)$ & $63.0(15.8)$ & 0.759 \\
\hline Sex (\%F/M) & $61 / 64$ & $3 / 18$ & 0.053 \\
\hline Smoker & $64 / 110$ & $13 / 18$ & 0.265 \\
\hline Diabetes mellitus & $57 / 110$ & $8 / 18$ & 0.774 \\
\hline Hypertension & $55 / 110$ & $10 / 18$ & 0.662 \\
\hline Coronary artery disease & $16 / 110$ & $2 / 18$ & 0.699 \\
\hline Congestive heart failure & $3 / 110$ & $1 / 18$ & 0.533 \\
\hline Cerebrovascular disease & $7 / 110$ & $4 / 18$ & 0.037 \\
\hline Renal insufficiency & $13 / 110$ & $3 / 18$ & 0.566 \\
\hline Most severe symptom (claudication) & $26 / 110$ & $3 / 18$ & \\
\hline Most severe symptom (rest pain) & $11 / 110$ & $3 / 18$ & 0.626 \\
\hline Most severe symptom (tissue loss) & $73 / 110$ & $12 / 8$ & \\
\hline Number of disease ( unilevel ) & $3 / 110$ & $1 / 18$ & 0.756 \\
\hline Number of disease (multilevel) & $107 / 110$ & $17 / 18$ & \\
\hline Mean ABI/ contralateral ABI & $0.53 / 0.86$ & $0.46 / 0.82$ & $0.417,0.532$ \\
\hline Poorly controlled DM & $14 / 71$ & $3 / 12$ & 0.046 \\
\hline
\end{tabular}

Table 1: Patient baseline characteristics. amputation in one year and coronary artery diseases, congestive heart failure (during hospital period).

For surgical procedures, there was no significance in comparing by type of inflow, outflow and types of graft in both groups.

\section{Discussion}

Although there was a trend for increased risk of amputation for patients with a history of smoking, DM, renal dysfunction, presenting with rest pain, lower ABI, multilevel disease, circumferential thickening of the stenosis, and lower risk for patients taking postoperative antiplatelets (but not anticoagulants), the only significant risk factor at the $5 \%$ level were poorly controlled diabetes mellitus after operation and cerebrovascular disease.

Dormandy et al. [15] showed a 5-year survival rate of $70 \%$ in patients with intermittent claudication while other studies reported a 5 -year survival rate of 38 to $48 \%$ for patients with critical leg ischemia treated surgically [16]. Al-Omran et al. [8] showed 5-year cumulative survival rate of $61.5 \%$ and major amputation-free survival rate of $83.4 \%$, compared with $69 \%$ and $92.2 \%$ in patients who underwent angioplasty. Male sex, older age, diabetes, and heart disease were associated with increased risk for death after revascularization procedure [8]. Increased risk of major amputation after revascularization procedures was associated with male sex, older age, and diabetes where as hypertension was linked to decreased risk. However, because of absence of clinical indications (intermittent claudicating or ischemia) for intervention in the databases, comparison between survival rates for these procedure reports is not possible $[17,18]$.

Ages [19-21], male sex [20-22], coronary artery disease [19,21,23], diabetes [5,18], and hypertension [23-26] have all been reported as predictors for increased mortality in patients with PAOD. The most significant factor in our study was poorly controlled diabetes mellitus when compared to other factors such as patients with history of smoking, diabetes mellitus, renal dysfunction, presenting with rest pain, lower ABI, multilevel disease, circumferential thickening of the stenosis. The risk was lower in patients who were taking postoperative antiplatelets (but not in anticoagulant group).

PAOD in diabetic patient (DM) progress more rapidly and more severely than non-diabetic patient [27]. DM compromises endothelial function by several mechanisms i.e., hyperglycemia, excess circulation of free fatty acid, increased oxidative stress, decreased nitric oxide synthesis and prostacyclin [27]. DM also augments the unstable atheroma formation due to secretion of cytokine by diabetic endothelial cell that inhibits collagen production of smooth muscle cell [28]. Fibrinolytic activity is impaired in DM which favors a tendency to coagulate and persistent thrombin formation [29]. All these pathophysiological mechanisms are important reasons that explain the significance of poorly controlled DM in lower limb amputation after bypass surgery.

Limitation of this retrospective study was that we couldn't control many parameters because of small volume of patients, making many well known risk factors not significant for amputation. However this study provides more clinically accepted estimates of outcome of revascularization procedures at the population level, which may be of great interest to patients undergoing revascularization to treat PAOD. Physicians could use survival and amputation-free survival rate and factors that influence them to explain to patient the long term outcome of revascularization procedures. 
Citation: Wilasrusmee C, Lebkhao P, Lertsittichai P, Proprom N (2012) Factors Affecting Lower Limb Amputation following Arterial Bypass Surgery. J Diabetes Metab 3: 208. doi:10.4172/2155-6156.1000208

Page 3 of 3

In future we will extend this study to increase the number of patients enrolled that impact on factors affecting the outcome of revascularization procedures and searching for other factors influencing amputation free survival rate or significant parameters that may predict outcome of revascularization procedures.

\section{Acknowledgement}

Study concept and design: Chumpon Wilasrusmee

Acquisition of data: Piya Lebkhao, Napaphat Proprom

Analysis and interpretation of data: Chumpon Wilasrusmee, Panuwat Lertsittichai

Drafting of the manuscript: Chumpon Wilasrusmee

\section{References}

1. Maini BS, Mannick JA (1978) Effect of arterial reconstruction on limb salvage: a ten-year appraisal. Arch Surg 113: 1297-1304.

2. Codd JE, Barner HB, Kaminski DL, Ramey A, Garvin PJ, et al. (1979) Extremity revascularization: a decade of experience. Am J Surg 138: 770-776.

3. Gresele P, Busti C, Fierro T (2011) Critical limb ischemia. Intern Emerg Med 1: 129-134.

4. Mattes E, Norman PE, Jamrozik K (1997) Falling incidence of amputions for peripheral occlusive arterial disease in western Australia between 1980 and 1992. Eur J Vasc Endovasc Surg 13: 14-22.

5. Dormandy JA, Rutherford RB (2000) Management of peripheral arteria disease (PAD). TASC Working Group. Trans Atlantic Inter-Society Consensus (TASC). J Vasc Surg 31: S1-S296.

6. Collins TC, Johnson M, Henderson W, Khuri SF, Daley J (2002) Lower extremity nontraumatic amputation among veterans with peripheral arterial disease: is race an independent factor. Med Care 40: I106-|116.

7. Zaraca F, Ponzoni A, Sbraga P, Ebner JA, Giovannetti R, et al. (2012) Factors affecting long-term outcomes after thromboembolectomy for acute lower limb ischemia. Minerva Chir 67: 49-57.

8. Al-Omran M, Tu JV, Johnston KW, Mamdani MM, Kucey DS (2003) Outcome of revascularizdion procedure for peripheral arterial occlusive disease in Ontario between 1991 and 1998: A population-based study. J Vasc Surg 38: 279-288.

9. Ebskov LB, Schroeder TV, Holstein PE (1994) Epidemiology of amputation the influence of vascular surgery. Br J Surg 81: 1600-1603.

10. Hallett JW Jr, Byrne J, Gayari MM, Ilstrup DM, Jacobsen SJ, et al. (1997) Impact of arterial surgery and balloon angioplasty on amputation: a population based study of 1155 procedures between 1973 and 1992. J Vasc Surg 25: 29-38.

11. Pell JP, Fowkes FG, Ruckley CV, Clarke J, Kendrick S, et al. (1994) Declining incidence of amputation for arterial disease in Scotland. Eur J Vasc Surg 8: 602-606.

12. Jaar BG, Astor BC, Berns JS, Powe NR (2004) Predictors of amputatlon and survival following lower extremity revascularization in hemodialyris patients. Kidney Int 65: 613-620.

13. Wrobel JS, Mayfield JA, Reiber GE (2001) Geographic Variation of LowerExtremity Major Amputation in Individuals with and without Diabetes in the Medicare Population. Diabetes Care 24: 860-864.

14. O'Hare AM, Sidawy AN, Feinglass J, Merine KM, Daley J, et al. (2004) Influence of renal insufficiency on limb loss and mortality after initial lower extremity surgical revascularization. J Vasc Surg 39: 709-716.

15. Dormandy J, Heeck L, Vig S (1999) The natural history of claudication: risk to life and limb. Semin Vasc Surg 12: 123-137.

16. Ndhler MR, Taylop LM, Monet GL, Pobter JM (1998) NatuRal history, nonoperative treatment, and functional assessment in chronic lower extpemity ischemia. IN: Moore WS, editor. Vascular surgery a comprehensive review 5th ed. Philadelphia: WB Saunders: 251-265

17. Malone JM, Moore WS, Goldstone J (1977) Life expectancy following aortofemoral arterial grafting. Surgery 81: 551-555.
18. Crawford ES, Bomberger RA, Glaeser DH, Saleh SA, Russell WL (1981) Aortoiliac occlusive disease: factors influencing survival and function following reconstructive operation over a twenty-five-year period. Surgery 90: 10551067

19. Banerjee AK, Pearson J, Gilliland EL, Goss D, Lewis JD, et al. (1992) A six year prospective study of fibrinogen and other risk factors associated with mortality in stable claudicants. Thromb Haemost 68: 261-263.

20. Faulkner KW, House AK (1981) Comparative survival rates in symptomatic peripheral vascular disease and colorectal cancer. Aust N Z J Surg 51: 152 156.

21. Cheng SW, Ting AC, Lau H, Wong J (2000) Survival in patients with chronic lower extremity ischemia: a risk factor analysis. Ann Vasc Surg 14: 158-165.

22. Hooi JD, Stoffers HE, Knottnerus JA, van Ree JW (1999) The prognosis of non-critical limb ishcaemia: a systemic review of population based evidence. Br J Gen Pract 49: 49-55.

23. Dormandy JA, Murray GD (1991) The fate of the claudicant: a prospective study of 1969 claudicants. Eur J Vasc Surg 5: 131-133.

24. DeWeese JA, Rob CG (1977) Autogenous vein grafts ten years later. Surgery 6: $775-784$

25. Szilagyi DE, Elliott JP Jr, Smith RF, Reddy DJ, McPharlin M (1986) A thirty year survey of the reconstructive surgical treatment of aortoiliac occlusive disease. J Vasc Surg 3: 421-436.

26. Jelnes R, Gaardsting O, Hougaard Jensen K, Baekgaard N, Tønnesen KH, et al. (1986) Fate in intermittent claudication: outcome and risk factors. Br Med J (Clin Res Ed) 293: 1137-1140

27. Jude EB, Oyibo SO, Chalmers N, Boulton AJ (2001) Peripheral arterial disease in diabetic and nondiabetic patients: a comparison of severity and outcome. Diabetes Care 24: 1433-1437.

28. Beckman JA, Creager MA, Libby $P$ (2002) Diabetes and atherosclerosis epidemiology, pathophysiology, and management. JAMA 287: 2570-2581.

29. Carr ME (2001) Diabetes mellitus: a hypercoagulable state. J Diabetes Complications 15: 44-54. 